\title{
Outcomes following necrotising fasciitis: an 8-year review
}

\author{
Hannah Watson*, Sameena Hassan and Michaela Davies \\ *Correspondence: hannahwatson1@nhs.net

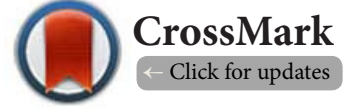

Department of Plastic and Reconstructive Surgery, Aberdeen Royal Infirmary, Aberdeen, AB25 2ZN, UK.

\begin{abstract}
Background: Necrotising soft tissue infections (NSTI) are uncommon and remain a devastating disease. This study aims to document mortality rates, assess the value of the laboratory risk indicator for necrotising fasciitis (LRINEC) score as a diagnostic tool and examine outcomes following reconstructive surgery for wound closure.

Methods: A retrospective case note review of patients presenting to our institute between 2004 and 2012 with a histological or clinical diagnosis of necrotising fasciitis were identified.

$\underline{\text { Results: }}$ Thirty-three patients with primary NSTI were identified with a male to female ratio of 1.6:1 and an average age of 50 years. Two patients with secondary reconstruction were identified with a male to female ratio of $1: 1$ and an average age of 63 years. Twenty patients required admission to the intensive care unit. On average each patient required two tissue debridements under anaesthesia to achieve a healthy wound base suitable for reconstruction. Reconstruction with an anterolateral fasciocutaneous thigh flap (ALT) was carried out in two patients (6\%), delayed split skin grafting in thirteen patients (39\%) and limb amputation in three patients (9\%). Partial flap loss with skin necrosis requiring debridement and advancement occurred in both patients who underwent ALT, whilst complete loss of skin graft occurred in one patient. Thirty-day mortality was $27 \%$ with an average time from presentation to death approximately 5 days.
\end{abstract}

Conclusion: Our experience of managing necrotising soft tissue infections has been mixed. Early diagnosis and aggressive debridement with frequent monitoring and return to theatre are essential. These interventions must be coupled with early administration of antimicrobials and supportive fluid resuscitation to provide optimal treatment in the care of NSTI patients.

Keywords: Necrotising fasciitis, mortality, antimicrobials, soft tissue infections

\section{Introduction}

Necrotising soft tissue infections (NSTI) are uncommon and remain a devastating disease, with an overall incidence of 0.24 0.4 per 100,000 adults $[1,2]$. Delays in instigation of appropriate treatment are associated with significant long-term morbidity with mortality ranging from $9 \%$ to more than $25 \%[3,4]$. Early and repeated debridement of affected planes in combination with use of broad-spectrum antibiotics improves overall outcome [5]. However, early NSTI can be difficult to distinguish from non-necrotising soft tissue infections in the absence of severe sepsis, multiorgan failure or pain. Significant risk factors for mortality have been predicted as age over 50 years, raised serum creatinine, delayed surgical intervention, multiorgan failure and elevated blood lactate [5,6]. Clinical features typical of a diagnosis of NSTI include agonising pain as the cutaneous nerve supply to overlying skin is destroyed, tenderness beyond erythematous areas, blister or bullae formation, swelling of muscle compartments which may give rise to a compartment syndrome and rapid progression of invading microorganisms through tissue planes $[7,8]$.

Our institute receives patients from a wide geographical range incorporating the Highlands and Islands of the United Kingdom. This study aims to document trends in causative organisms of NSTI and mortality rates, assess the value of the laboratory risk indicator for necrotising fasciitis (LRINEC) score as a diagnostic tool and examine outcomes following recon- 
Watson et al. Research Journal of Infectious Diseases 2014,

structive surgery for wound closure.

\section{Methods}

A retrospective case note review of patients presenting to our institute between 2004 and 2012 with a diagnostic code of necrotising fasciitis (NF) were identified from medical records. Notes were examined to ensure that an operative or pathological diagnosis of NF was recorded. Cases transferred to our institution for secondary reconstruction are reported separately.

\section{Results}

Thirty-three patients with primary NSTI and two patients referred for secondary reconstruction were identified with a male to female ratio of 1.6:1 and 1:1; and average age of 50 and 63 years in primary referral (PR) and secondary reconstruction (SR) respectively. Average length of inpatient care was 39 days (range $0-210$ ) in PR and 45.5 days in SR.

\section{Primary referral \\ Admission co-morbidities}

Patients presented to our institute with onset of symptoms averaging 4 days prior to admission with a mean early warning score of just 1.5 (range $0-6$ ). Eight patients (24\%) were intravenous drug users; there were no mortalities in this group. Nine patients were diabetic; four patients had infectious diseases including hepatitis $A, B, C$ and human immuno-deficiency virus, whilst three patients had a history of mental health illness. Nine patients had an underlying respiratory disease, two patients suffered motor deficit due to a prior cerebrovascular accident, two patients had underlying liver disease and three patients had ischaemic heart disease.

\section{Laboratory risk indicator for necrotising fasciitis}

The LRINEC score was applied retrospectively, where a score of 6 or above has a positive predictive value of $92 \%$ [9]. Twenty patients $(60 \%)$ in our study met these criteria, whilst thirteen patients (40\%) scored under. Fourteen patients (42\%) had an admission differential diagnosis that included NSTI, these patients scored 8 or above on the LRINEC scale.

\section{Causative organisms}

Sixteen patients (48\%) grew polymicrobial organisms on tissue culture, whilst organisms causing monomicrobial infections included Clostridium perfringens, Enterococcus faecalis, Escherichia coli, Staphylococcus aureus, groups A and B Streptococcus and Streptococcus milleri. Table 1 describes all organisms cultured from infected tissue at first debridement. Hospital acquired infection occurred in 12 patients (36\%) resulting in polymicrobial infections across multiple body systems including blood, urinary and respiratory tract infections. There was one documented case of hospital acquired methicillin-resistant Staphylococcus aureus (MRSA); the other causative organisms are described in Graph 1.
Table 1. All microorganisms grown at first debridement for primary referral necrotising fasciitis patients.

\begin{tabular}{ll}
\hline \multicolumn{2}{c}{ Cultured Microorganism } \\
\hline Monomicrobial & Polymicrobial \\
\hline Coliforms & Candida species \\
Clostridium species & Clostridium species \\
Enterococcus faecalis & Coliforms \\
Escherichia coli & Enterococcus faecalis \\
Mixed anaerobes & Proteus \\
Staphylococcus aureus & Pseudomonas aeruginosa \\
Streptococcus Group A & Staphylococcus aureus \\
Streptococcus Group B & Streptococcus alpha-haemolytic \\
Streptococcus milleri & Stretococcus milleri \\
\hline
\end{tabular}

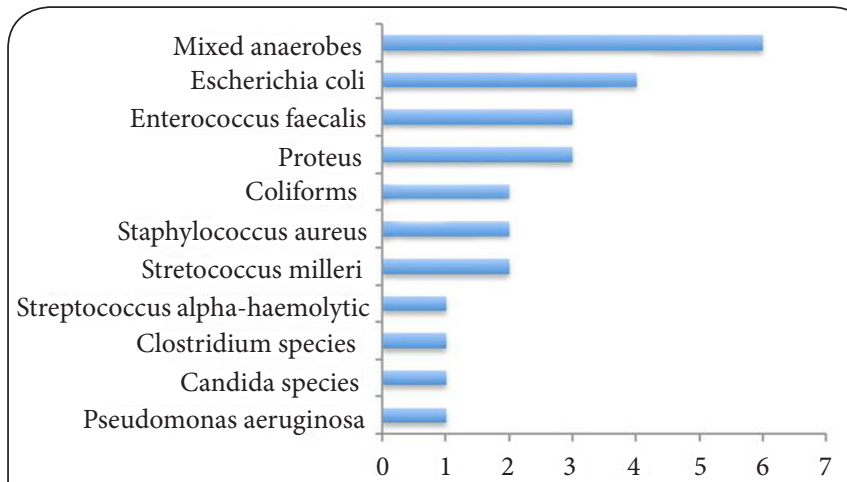

Graph 1. Causative organisms resulting in hospital acquired infections indicating the number of patients affected.

\section{Antibiotic administration}

Administration of appropriate intravenous antibiotics within one hour of recognition of septic shock is the gold standard set out by the surviving sepsis campaign [10]. Six patients (18\%) met this target whilst seven patients (21\%) waited more than 4 hours. Wide discrepancies exist in antimicrobial prescribing practices. Where there was an immediate recognition of necrotising fasciitis commonly prescribed antimicrobials where flucloxacillin, benzylpenicillin, metronidazole, clindamycin and gentamicin in combination. Where a cellulitis was diagnosed but NF not considered, gram-negative organisms or anaerobes where not routinely covered and combinations of flucloxacillin, benzylpenicillin and clindamycin were used. Nine patients were switched to combinations of meropenem and tazocin as their condition deteriorated. In our practice, once initial broad-spectrum antimicrobials have been administered, further doses are with held until an urgent gram stain of infected tissues can be processed. Continued antimicrobial therapy depends on organisms isolated, there is a low threshold to cover anaerobic microorganisms, particularly in groin wounds.

\section{Surgical outcomes}

Average total body surface area affected was $6 \%$ (range 1-18), 
with sites including upper limb (6\%), trunk (19\%), lower limb (48\%) and perineum (27\%). On average each patient required two tissue debridements under anaesthesia to achieve a healthy wound base suitable for reconstruction. Twenty patients required admission to the intensive care unit (ITU), with 127 days total ITU care. A total of 157 units of red blood cells were used in fluid resuscitation with six patients requiring massive transfusion with concomitant support with fresh frozen plasma and platelets; all these patients survived. Where delayed wound closure was possible, this was generally undertaken when the patient had stabilized, was out of an ITU setting and off inotropic support. Reconstruction with an anterolateral fasciocutaneous thigh flap (ALT) was carried out in two patients $(6 \%)$, delayed split skin grafting in thirteen patients (39\%) and limb amputation in three patients (9\%). Partial flap loss with skin necrosis requiring debridement and advancement occurred in both patients who underwent ALT, whilst complete loss of skin graft occurred in one patient.

\section{Medical outcomes}

Many of these patients developed secondary medical problems requiring specialist input. Six patients (18\%) developed acute kidney injury of which two required dialysis support whilst three patients (9\%) suffered an acute coronary event. Other medical sequelae included neutropenic sepsis, lung collapse, pneumonia, acute lung injury, gastrointestinal bleed and lower leg deep vein thrombosis. A minority of patients also required long-term nutritional support in the form of percutaneous endoscopic gastroscopy feeding tubes. Long-term morbidity included eight cases of colostomy formation, one patient with chronic lower limb lymphoedema and one patient who required long-term suprapubic catheter insertion.

\section{Mortality rate}

Thirty-day mortality was $27 \%$ (9 patients) and average time from presentation to death was approximately 5 days. Fifteen patients (45\%) were obese, of which three patients died and two $(6 \%)$ were morbidly obese, of which one patient died. Anatomical site of NSTI in deceased patients was upper limb (1), trunk (3), lower limb (4) and perineum (1). Three mortalities arose in patients debrided within 24 hours compared with two mortalities in patients debrided in less than 4 hours.

\section{Secondary reconstruction}

Two patients were referred to our unit for delayed surgical reconstruction, having been debrided and stabilized elsewhere. Both patients grew polymicrobial organisms from their wound bed including extended-spectrum beta-lactamases (ESBL) and MRSA. Both patients underwent split skin grafting with early failure rates, likely due to bacterial contamination of the wound bed.

\section{Discussion and conclusion}

Our experience of managing necrotising soft tissue infections has been mixed. Essential components of successful treatment include early diagnosis plus aggressive debridements with frequent monitoring and return to theatre, as appropriate. To maximise positive patient outcomes surgical management has to be coupled with stringent medical interventions, namely early administration of broad-spectrum antimicrobials and supportive fluid resuscitation. Early treatment improves patient outcomes [5], but NSTI can be difficult to distinguish from cellulitis and abscesses. As such, less than half of our patients had an admission diagnosis of NSTI, which may account for the wide discrepancies seen in antibiotic therapy. Despite a diverse surviving sepsis campaign, the door to needle time in our cohort of patients remains poor.

Myocutaneous or fasciocutaneous flap reconstruction of large areas confers the benefit of avoiding skin graft contractures that may later require release. The use of flap cover following NF has been reported in the literature [11-13]. Whilst the tip of the flap was prone to necrosis in both of our cases, overall the patients went on to have a satisfactory cosmetic outcome with adequate wound coverage and minimal donor site morbidity. Skin flap necrosis is a recognised complication of local flaps, especially when raising large flaps on distal perforators. In our reconstructed cases, although there was no evidence of overt pus on revision surgery, ongoing infection can compromise the small calibre vessels that supply the skin leading to ischaemia [14]. In addition, there may be a local inflammatory response that persists beyond debridement compromising vasculature of neighbouring tissue. Use of vacuum assisted closure combined with frequent change of dressing and debridement of non-viable tissue with delayed wound closure is the mainstay of treatment for the majority of cases of necrotising fasciitis [15-17]. In our small series of delayed secondary reconstruction, neither patient had a wound bed that supported a graft despite repeated debridements. These patients grew ESBL and MRSA on tissue culture. Open wounds allow colonization and invasion of resistant microorganisms and are difficult wounds to treat. These may be best served with prolonged vacuum assisted closure (VAC) therapy or closure by secondary intention with revision for cosmesis at a later date once the eradication of organisms is ensured.

Just over half of our patients met the LRINEC criteria for diagnosis of NSTI. The LRINEC scoring system was first described by Wong et al., and is based on the serum markers of C-reactive protein, haemoglobin, white blood cell count, sodium, creatinine and plasma glucose. The original paper by Wong et al., claims a positive predictive value for NSTI of $92 \%$ and a negative predictive value of $96 \%$, although subsequent authors were unable to replicate this success [18]. Determining the score requires a suspicion of NF in the first place, for those patients where NF was not within the admission differential diagnosis the LRINEC score could not be accurately scored. Commonly, admission glucose levels were untested or not documented.

NSTI is a prime example of a condition requiring multiisciplinary 
Watson et al. Research Journal of Infectious Diseases 2014,

http://www.hoajonline.com/journals/pdf/2052-5958-2-5.pdf

input throughout the duration of treatment. In our patient cohort up to eight specialties were involved in each individual case. Within these disciplines were dieticians, microbiologists, psychiatrists and individual medical specialties. Our mortality rates are comparable to published series in the literature [19]. NSTI patients follow a predictive path of extensive fluid resuscitation, electrolyte imbalance, acute lung and kidney injury and cardiogenic shock. As such, early and continued input from specialty services is imperative to successful outcomes.

\section{Competing interests}

The authors declare that they have no competing interests.

Authors' contributions

\begin{tabular}{|l|c|c|c|}
\hline Authors' contributions & HW & SH & MD \\
\hline Research concept and design & -- & $\checkmark$ & -- \\
\hline Collection and/or assembly of data & $\checkmark$ & -- & -- \\
\hline Data analysis and interpretation & $\checkmark$ & $\checkmark$ & -- \\
\hline Writing the article & $\checkmark$ & -- & -- \\
\hline Critical revision of the article & $\checkmark$ & $\checkmark$ & -- \\
\hline Final approval of article & -- & $\checkmark$ & $\checkmark$ \\
\hline Statistical analysis & -- & $\checkmark$ & -- \\
\hline
\end{tabular}

Publication history

Senior Editor: Isaac Karimi, Razi university, Iran.

EIC: Ishtiaq Qadri, King Abdul Aziz University, Saudi Arabia.

Received: 18-Jun-2014 Final Revised: 18-Sep-2014

Accepted: 13-Oct-2014 Published: 18-Oct-2014

\section{References}

1. O'Brien KL, Beall $B$ and Barrett NL. Epidemiology of invasive group $A$ streptococcal necrotizing fasciitis. Clin Infect Dis. 2004; 36:610-622.

2. Kaul R, McGeer A, Low DE, Green K and Schwartz B. Population-based surveillance for group A streptococcal necrotizing fasciitis: Clinical features, prognostic indicators, and microbiologic analysis of seventyseven cases. Ontario Group A Streptococcal Study. Am J Med. 1997; 103:18-24. | Article | PubMed

3. Kao LS, Lew DF, Arab SN, Todd SR, Awad SS, Carrick MM, Corneille MG and Lally KP. Local variations in the epidemiology, microbiology, and outcome of necrotizing soft-tissue infections: a multicenter study. Am J Surg. 2011; 202:139-45. | Article | PubMed Abstract | PubMed Full Text

4. Elliott $D$, Kufera JA and Myers RA. The microbiology of necrotizing soft tissue infections. Am J Surg. 2000; 179:361-6. | Article | PubMed

5. Elliott DC, Kufera JA and Myers RA. Necrotizing soft tissue infections. Risk factors for mortality and strategies for management. Ann Surg. 1996; 224:672-83. | Article | PubMed Abstract | PubMed Full Text

6. V K, Hiremath $B V$ and V Al. Necrotising soft tissue infection-risk factors for mortality. J Clin Diagn Res. 2013; 7:1662-5. | Article | PubMed Abstract I PubMed Full Text

7. Morgan MS. Diagnosis and management of necrotising fasciitis: a multiparametric approach. J Hosp Infect. 2010; 75:249-57. | Article | PubMed

8. Shiroff AM, Herlitz GN and Gracias VH. Necrotizing soft tissue infections. J Intensive Care Med. 2014; 29:138-44. | Article I PubMed

9. Wong $\mathrm{CH}$, Khin LW, Heng KS, Tan KC and Low CO. The LRINEC (Laboratory Risk Indicator for Necrotizing Fasciitis) score: a tool for distinguishing necrotizing fasciitis from other soft tissue infections. Crit Care Med. 2004; 32:1535-41. | Article | PubMed

10. Dellinger RP, Levy MM, Rhodes A, Annane D, Gerlach H, Opal SM,
Sevransky JE, Sprung CL, Douglas IS, Jaeschke R, Osborn TM, Nunnally ME, Townsend SR, Reinhart K, Kleinpell RM, Angus DC, Deutschman CS, Machado FR, Rubenfeld GD, Webb SA, Beale RJ, Vincent JL and Moreno $R$. Surviving sepsis campaign: international guidelines for management of severe sepsis and septic shock: 2012. Crit Care Med. 2013; 41:580637. | Article | PubMed

11. Hughes T, Yu JT, Wong KY and Malata CM. "Emergency" definitive reconstruction of a necrotising fasciitis thigh debridement defect with a pedicled TRAM flap. Int I Surg Case Rep. 2013; 4:453-5. | Article | PubMed Abstract | PubMed Full Text

12. Alexander $K$, Lawton $G$ and Macquillan $A$. A pedicled latissimus dorsi myocutaneous flap for early reconstruction of cervicocranial necrotising fasciitis. Indian J Plast Surg. 2010; 43:224-5. | Article | PubMed Abstract PubMed Full Text

13. Duman $\mathrm{H}$, Kayahan $\mathrm{C}$ and Celikoz B. Reconstruction of a large abdominal wall defect resulting after necrotizing fasciitis with free latissimus dorsi flap. Eur J Plast Surg. 2000; 23:91-93. | Article

14. Chen HC and Tang YB. Anterolateral thigh flap: an ideal soft tissue flap. Clin Plast Surg. 2003; 30:383-401. | Article | PubMed

15. Assenza M, Cozza V, Sacco E, Clementi I, Tarantino B, Passafiume $F$ Valesini L, Bartolucci P and Modini C. VAC (Vacuum Assisted Closure) treatment in Fournier's gangrene: personal experience and literature review. Clin Ter. 2011; 162:e1-5. | Article | PubMed

16. Steinstraesser L, Sand M and Steinau HU. Giant VAC in a patient with extensive necrotizing fasciitis. Int J Low Extrem Wounds. 2009; 8:28-30. | Article | PubMed

17. Kumar S, O'Donnell ME, Khan K, Dunne G, Carey PD and Lee J. Successful treatment of perineal necrotising fasciitis and associated pubic bone osteomyelitis with the vacuum assisted closure system. World J Surg Oncol. 2008; 6:67. | Article | PubMed Abstract | PubMed Full Text

18. Anaya DA, McMahon K, Nathens AB, Sullivan SR, Foy H and Bulger E. Predictors of mortality and limb loss in necrotizing soft tissue infections. Arch Surg. 2005; 140:151-7; discussion 158. | Article | PubMed

19. Holland MJ. Application of the Laboratory Risk Indicator in Necrotising Fasciitis (LRINEC) score to patients in a tropical tertiary referral centre. Anaesth Intensive Care. 2009; 37:588-92. | PubMed

Citation:

Watson H, Hassan S and Davies M. Outcomes following necrotising fasciitis: an 8-year review. Res J Infect Dis. 2014; 2:5. http://dx.doi.org/10.7243/2052-5958-2-5 